\title{
Fluorescein angiography and its prognostic significance in central retinal vein occlusion
}

\author{
L. LAATIKAINEN AND E. M. KOHNER \\ From the Retinal Diagnostic Unit, Moorfields Eye Hospital, London
}

There are three principal reactions of retinal blood vessels to veno-occlusive disease: dilatation of retinal veins and capillaries, abnormal vascular permeability, and vascular non-perfusion primarily affecting the capillaries. Fluorescein angiography permits localization and qualitative evaluation of abnormal vascular permeability (Gass, I968). It shows clearly perfused capillaries and delineates areas of non-perfusion. The degree of capillary dilatation can be gauged by comparing the affected with the normal eye (dilatation of capillaries is usually associated with non-perfusion of others).

In order to determine the relevance of the various abnormalities observed on fluorescein angiograms in central retinal vein occlusion (CRVO) a prospective study was undertaken correlating the fluorescein angiographic findings with the final status of the eyes affected. The results are presented in this paper.

\section{Patients and methods}

Seventy-five eyes of consecutive patients with CRVO referred to the Retinal Diagnostic Department of Moorfields Eye Hospital or to Hammersmith Hospital were followed-up. Eyes with associated major retinal vascular disease like diabetic retinopathy were excluded. None of the patients received any specific treatment for the occlusion for at least one year after presentation. Symptomatic treatment for complications such as thrombotic glaucoma was given as required. The initial examination was done within one month of the first visual symptom in 60 cases (in 37 during the first week) and during the second and third months in 15 cases. After the initial presentation most patients were studied at three, six, and 12 months after the onset of symptoms. Some of those presenting during the first month had additional studies performed at six to eight weeks. At each visit a full eye examination and retinal photography were performed.

For fluorescein photographs $5 \mathrm{ml}$ of 20 per cent sodium fluorescein was injected as fast as possible using either an antecubital intravenous injection or an intra-

This work was supported by the Wellcome Trust and the Francis and Renée Hock Foundation

Address for reprints: Dr E. M. Kohner, Retinal Diagnostic Unit, Moorfields Eye Hospital, London ECI venous catheter which was carried from the antecubital vein to the subclavian vein in order to get the best possible dye bolus in the retina.

\section{ANGIOGRAPHIC FEATURES RECORDED}

The following features were recorded in each fluorescein angiogram.

I. Presence, absence, localization, and extent of retinal non-perfusion. In retinal capillary non-perfusion central and peripheral areas of capillary closure were separated and the extent of non-perfusion was graded qualitatively as $o,+$, or ++ .

2. Completeness of perifoveal capillary arcade. The perifoveal capillary arcade was regarded as broken when a definite gap in its continuity was seen. In some cases it was impossible to assess the arcade fully in the first angiogram because of macular oedema or haemorrhage. In these eyes the intactness of the arcade was analysed later. Eyes in which no normal macular capillaries were present were recorded as a separate group.

3. Presence or absence of fluorescein leakage in the macular area and source of such leakage. Eyes with fluorescein leakage from postcapillary venules only but no obvious leakage from the perifoveal capillaries were separated from those with capillary leakage.

4. Qualitative estimation of leakage from main veins. Leakage from the main veins and the larger venous branches was graded as $0,+,++$, or +++ . The amount of venous dilatation was not measured or arbitrarily estimated.

5. Length of macular transit time. This was defined as the time between the first fluorescein appearance in the main retinal arteries and its appearance in the macular veins. In most healthy eyes the fluorescein appears in the macular veins within $1-2$ seconds of reaching the arteries. Therefore macular transit time of less than 2 seconds was regarded as 'normal' and 2 seconds or longer as 'delayed'.

\section{Disc or retinal new vessel formation.}

Arm to retina fluorescein circulation time was not compared with that of the normal eye because of inaccuracies due to variables in technical and circulatory factors.

\section{CLINICAL GROUPINGS}

The eyes were subdivided into the following five groups according to the one-year (final) visual acuity (VA), 


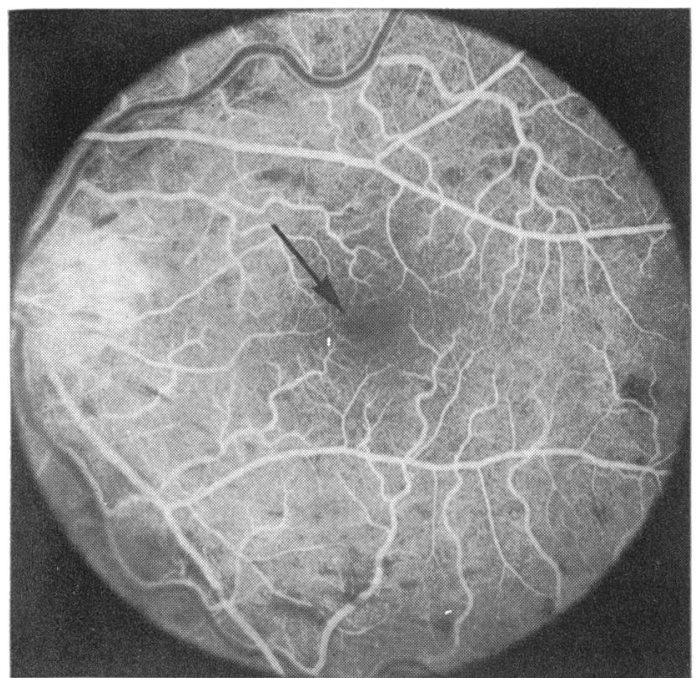

( $1 a)$

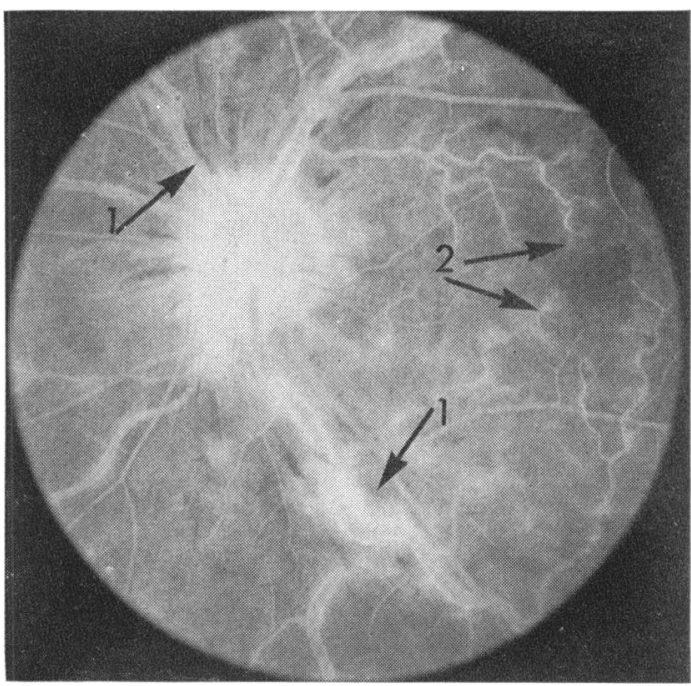

( 1 b)

FIG. I Mild CRVO. (a) Perifoveal capillary arcade nearly intact (arrow). (b) Same eye, late venous phase. Some leakage from main veins (arrows 1 ) and macular venules (arrows 2) but no obvious leakage from perifoveal capillaries

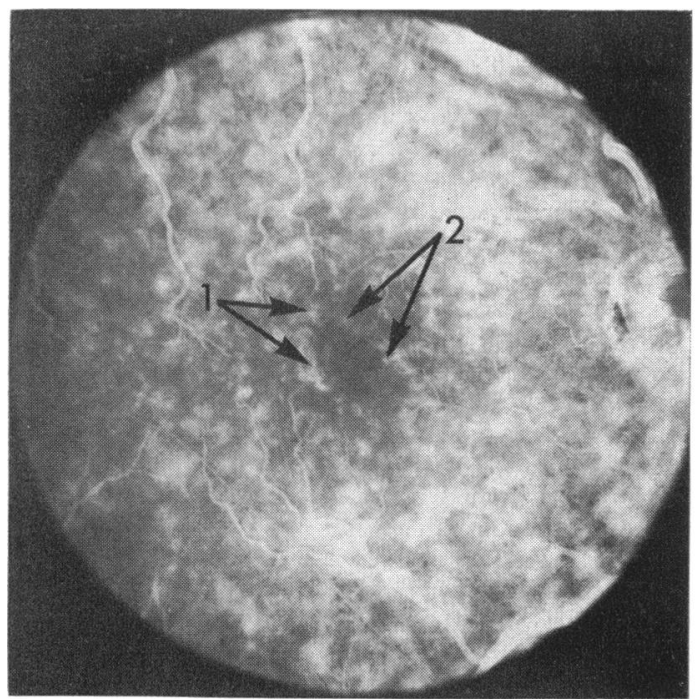

(2a)

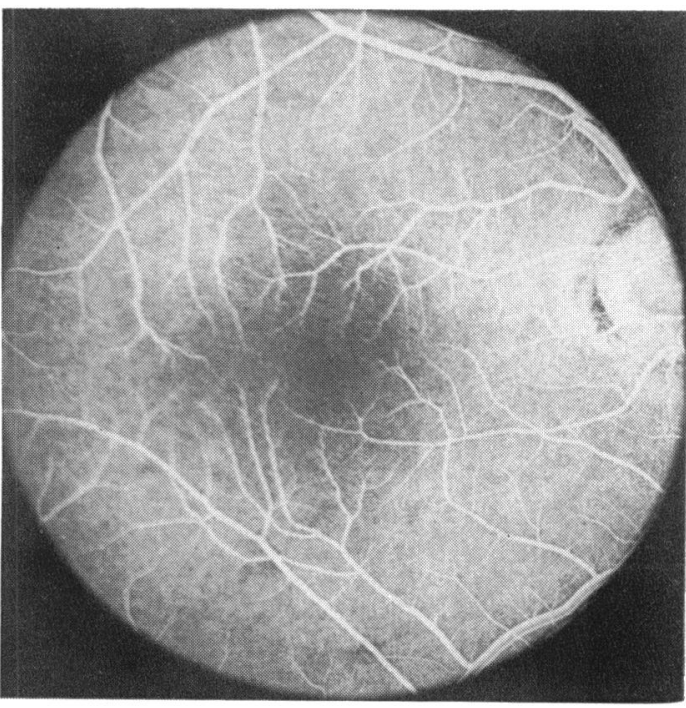

$(2 b)$

FIG. 2 CRVO in acute stage. (a) Both venules (arrow 1) and capillaries (arrow 2) leak fluorescein. (b) Same as Fig. 2a, I year later. Complete resolution without leakage

ophthalmoscopic changes, and complications. (I) Full resolution (VA 6/9 or better). (2) Partial resolution (VA $6 / 12-6 / 18$ ) with or without ophthalmoscopically visible late changes. (3) Maculopathy (VA 6/24 or less due to chronic macular oedema or pigment epithelial changes and foveal scarring). (4) Thrombotic glaucoma. (5) Other major complications such as proliferating retinopathy, vitreous haemorrhage, retinal detachment (and preretinal fibrosis).

\section{Results}

FULL RESOLUTION

In 15 of the 16 eyes with good final VA the initial fluorescein angiogram showed good retinal capillary perfusion. In one eye some small areas of nonperfusion were seen in the periphery (Table I). The perifoveal capillary arcade was intact or near intact 
Table I Correlation between final outcome and retinal capillary non-perfusion (initial examination)

\begin{tabular}{|c|c|c|c|c|c|c|c|}
\hline \multirow{2}{*}{ Final outcome } & \multirow{2}{*}{$\begin{array}{l}\text { No. of } \\
\text { eyes }\end{array}$} & \multicolumn{6}{|c|}{ Capillary non-perfusion } \\
\hline & & None & $C-/ P+$ & $C+/ P-$ & $C+P+$ & $C++\mid P++$ & Not known \\
\hline Full resolution & I6 & I 5 & $\mathbf{I}$ & - & - & - & - \\
\hline Partial resolution & 12 & 12 & - & - & - & - & - \\
\hline Maculopathy & 24 & I I & - & 7 & 6 & - & - \\
\hline Thrombotic glaucoma & I 3 & 2 & - & - & 3 & 7 & I \\
\hline Other complications & IO & $\mathbf{I}$ & - & I & $\mathbf{I}$ & 7 & - \\
\hline Total & 75 & 41 & I & 8 & 10 & I4 & I \\
\hline
\end{tabular}

$\mathrm{C}=$ Central areas of non-perfusion; $\mathrm{P}=$ Peripheral areas of non-perfusion; $+=$ Small areas; $++=$ Extensive areas

Table II Correlation between final outcome and completeness of perifoveal capillary arcade (initial study)

\begin{tabular}{|c|c|c|c|c|c|}
\hline \multirow[b]{2}{*}{ Final outcome } & \multirow[b]{2}{*}{$\begin{array}{l}\text { No. of } \\
\text { eyes }\end{array}$} & \multicolumn{4}{|c|}{ Perifoveal arcade } \\
\hline & & Intact & Broken & $\begin{array}{l}\text { No } \\
\text { capillaries }\end{array}$ & $\begin{array}{l}\text { Not } \\
\text { known }\end{array}$ \\
\hline Full resolution & I6 & 16 & - & - & - \\
\hline Partial resolution & 12 & II & I & - & - \\
\hline Maculopathy & 24 & I I & 12 & - & I \\
\hline Thrombotic & & & & & \\
\hline glaucoma & 13 & 2 & $\mathbf{I}$ & 8 & 2 \\
\hline Other complications & 10 & - & 2 & 7 & $\mathbf{I}$ \\
\hline Total & 75 & 40 & I6 & I 5 & 4 \\
\hline
\end{tabular}

Table III Correlation betzieen final outcome and macular leakage (initial study)

\begin{tabular}{|c|c|c|c|c|}
\hline \multirow{2}{*}{ Final outcome } & \multirow{2}{*}{$\begin{array}{l}\text { No. of } \\
\text { eyes }\end{array}$} & \multicolumn{3}{|c|}{ Macular leakage } \\
\hline & & None & Venular only & Capillary \\
\hline Full resolution & 16 & I I & 4 & $\mathbf{I}$ \\
\hline Partial resolution & 12 & 4 & 4 & 4 \\
\hline Maculopathy & 24 & 1 & I & 22 \\
\hline Thrombotic glaucoma & 13 & - & $10^{*}$ & 3 \\
\hline Other complications & ro & - & $8^{*}$ & 2 \\
\hline Total & 75 & I6 & 27 & 32 \\
\hline
\end{tabular}

*From remaining veins (no or only few capillaries perfused) in all eyes (Table II) and in I I out of 16 no leakage from the macular vessels was seen. The macular venules leaked fluorescein in five (Fig. $1 a, b$ ), and in one of these there was also some capillary leakage (Table III). Macular transit time was normal in nine eyes and delayed in seven; in two the delay was more than 5 seconds (Table IV). Mild and localized leakage from the major veins was seen in eight of these eyes.

\section{PARTIAL RESOLUTION}

In 12 eyes a final VA of $6 / 12$ to $6 / 18$ was achieved. The fluorescein angiographic findings in this group did not differ significantly from those in the previous group. Capillary perfusion was good in all cases (Table I) and the perifoveal capillary arcade was intact in all but one eye (Table II). However, in this group leakage from the macular vessels was more common despite the intact arcade. Venous leakage was found in four eyes and in four there was combined macular capillary and venous leakage (Fig. 2a, b). Leakage from the larger veins was more common and more pronounced than in the previous group (Table IV). Macular transit time was normal in eight eyes, delayed in two eyes, and in two eyes it could not be measured (Table IV).

Table IV Correlation between final outcome and macular transit time (seconds) and venous leakage (initial study)

\begin{tabular}{|c|c|c|c|c|c|c|c|c|c|}
\hline \multirow{2}{*}{ Final outcome } & \multirow{2}{*}{$\begin{array}{l}\text { No. of } \\
\text { eyes }\end{array}$} & \multicolumn{3}{|c|}{ Macular transit time } & \multicolumn{5}{|c|}{ Venous leakage } \\
\hline & & $<2 s$ & $>2 s$ & Not known & None & + & +1 & $++t$ & Not known \\
\hline Full resolution & I6 & 9 & 7 & - & 8 & 7 & I & - & - \\
\hline Partial resolution & 12 & 8 & 2 & 2 & 4 & 4 & 2 & 2 & - \\
\hline Maculopathy & 24 & 8 & 12 & 4 & I & 12 & 6 & 3 & 2 \\
\hline Thrombotic glaucoma & I 3 & $\mathbf{I}$ & 12 & 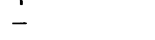 & I & 4 & 6 & 2 & - \\
\hline Other complications & I0 & - & Io & - & - & 2 & 6 & 2 & - \\
\hline Total & 75 & 26 & 43 & 6 & I 4 & 29 & 2 I & 9 & 2 \\
\hline
\end{tabular}

$+=$ Mild; $++=$ Moderate; $+++=$ Severe leakage 


\section{MACULOPATHY GROUP}

In I I of the 24 eyes in this group retinal capillary perfusion was good; no areas of non-perfusion were seen either in the centre or in the periphery (Fig. $3 a, b, c, d$ ). However in 13 eyes small areas of capillary closure were discovered at the posterior pole (Fig. $4 a, b, c$ ) and in six of them smaller peripheral non-perfused areas were also present (Table I). The perifoveal capillary arcade was

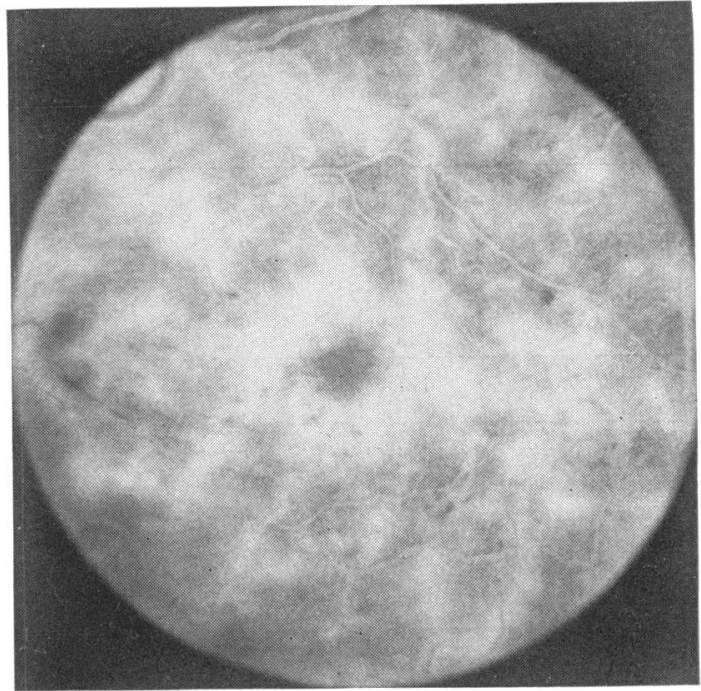

$(3 b)$

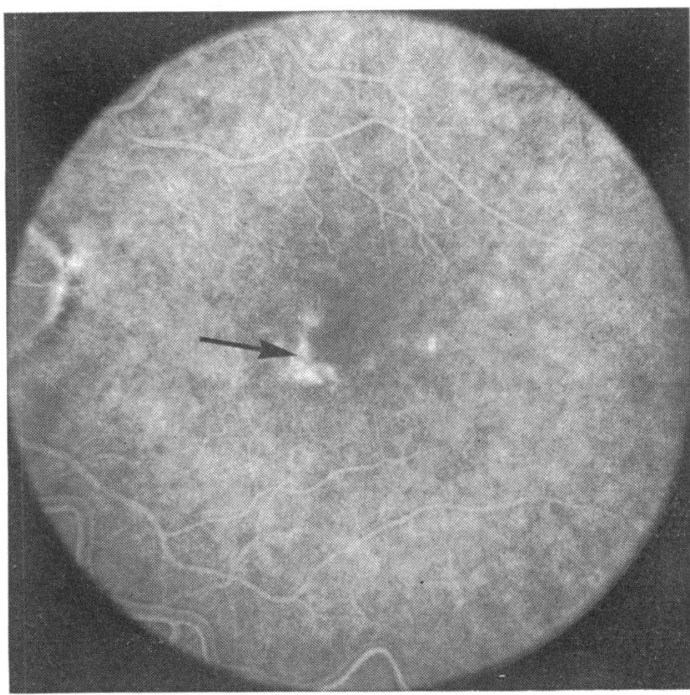

$(3 d)$

FIG. 3 CRVO of moderate severity in acute stage. (a) Early venous phase; perifoveal arcade broken. (b) Same angiogram as (a), late venous phase. Diffuse leakage from perifoveal capillaries and venules. (c) Same as (a) after resolution. Small area of non-perfused and dilated capillaries outside the fovea (arrow). (d) Same angiogram as (c), late venous phase. Mild leakage from dilated capillaries (arrow)

intact in $\mathrm{II}$ eyes, broken in $\mathrm{I} 2$, and could not be seen in one (Table II). Leakage from macular capillaries was seen in 22 eyes, whereas the venules leaked in only one, and in one eye there was no leakage (Table III). Leakage from the main veins was a regular finding but in half the cases the venous leakage was very mild. Macular transit time was normal in eight eyes, delayed in 12 (in four it was 5 seconds or more), and could not be measured in four (Table IV). 


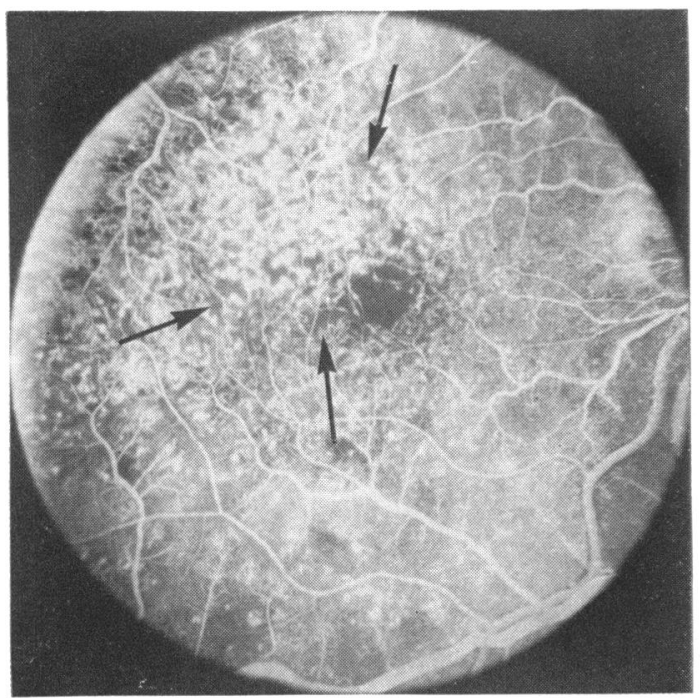

$(4 a)$

FIG. 4 CRVO of moderate severity 3 months after initial symptoms. (a) Perifoveal arcade broken, multiple small areas of capillary closure associated with dilated capillaries (arrows). (b) Same angiogram as (a), late venous phase. Extensive fluorescein leakage from dilated capillaries. (c) Same as (b) but I year later. More leakage in inferior nasal half of macula. Big retinociliary by-pass channel on disc (arrow)

\section{THROMBOTIC GLAUCOMA}

At the initial presentation central and peripheral capillary non-perfusion was almost complete in seven (Fig. $5 a, b$ ) of the 13 eyes in this group, and capillary non-perfusion was less but still extensive in a further three. In one eye the retinal details could not be seen. By contrast, the remaining two eyes had good capillary perfusion at the time of the initial study (Table I) but extensive nonperfusion developed during the first three months. Most eyes showed increasing capillary and small vessel closure compared with the acute stage (Fig. $6 a, b$ ). As a result, at the three-month examination there was extensive central and peripheral non-perfusion in 10 of the 13 eyes, considerable non-perfusion in one, and in two corneal oedema made further photography impossible.

In one of the two eyes in which capillary perfusion was initially good the perifoveal capillary arcade was also intact in the first angiogram but there was capillary leakage. In one eye the perifoveal arcade was broken, and in two eyes it could not be seen (Table II). Eight of 13 eyes had no or only a few macular capillaries remaining. Large vessels cros-

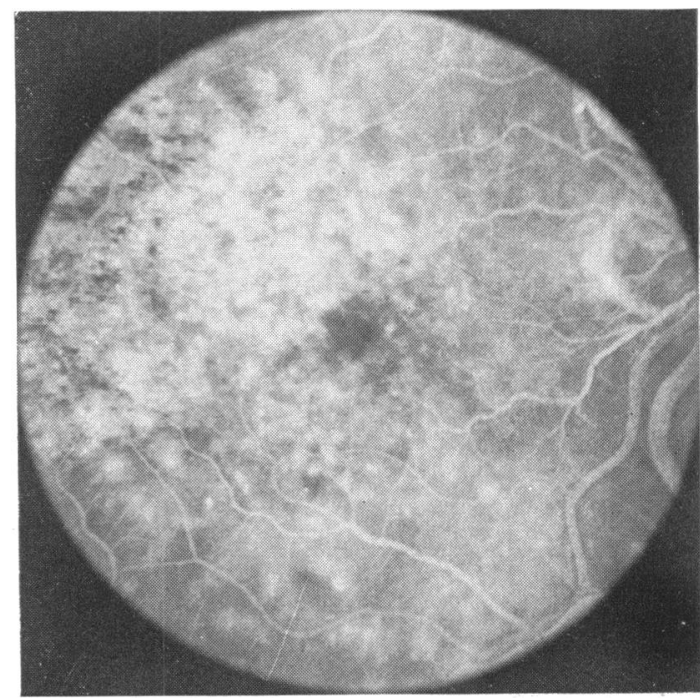

$(4 b)$

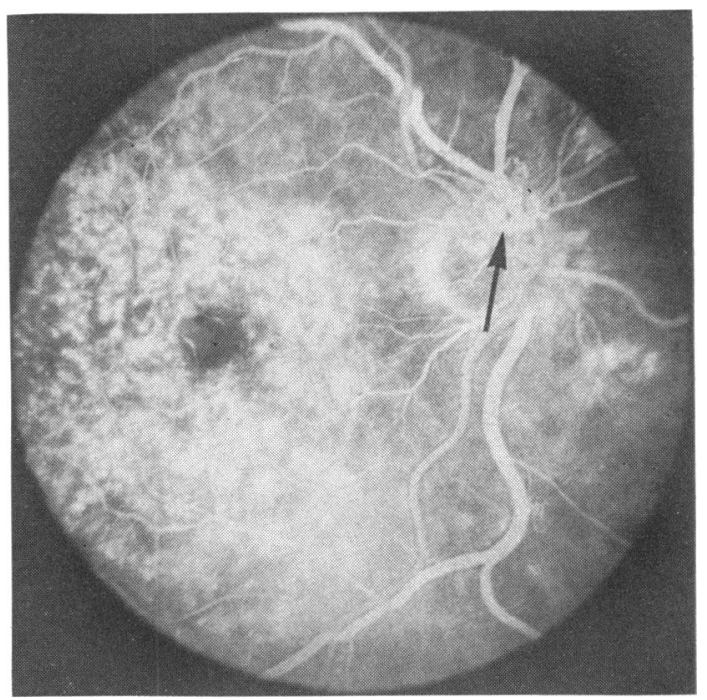

$(4 c)$

sing areas of capillary non-perfusion always leaked fluorescein (Fig. 5b).

\section{OTHER COMPLICATIONS}

Proliferating retinopathy was present in seven eyes and preretinal fibrosis in three. The findings in these eyes are discussed together because the subgroups are small and the fluorescein appearance similar. All except one eye, which developed preretinal fibrosis, had poor capillary perfusion (Table I); in seven of the ro eyes the central and peripheral capillary closure was extensive (Fig. $7 a, b)$. The perifoveal capillary arcade was broken in two, 


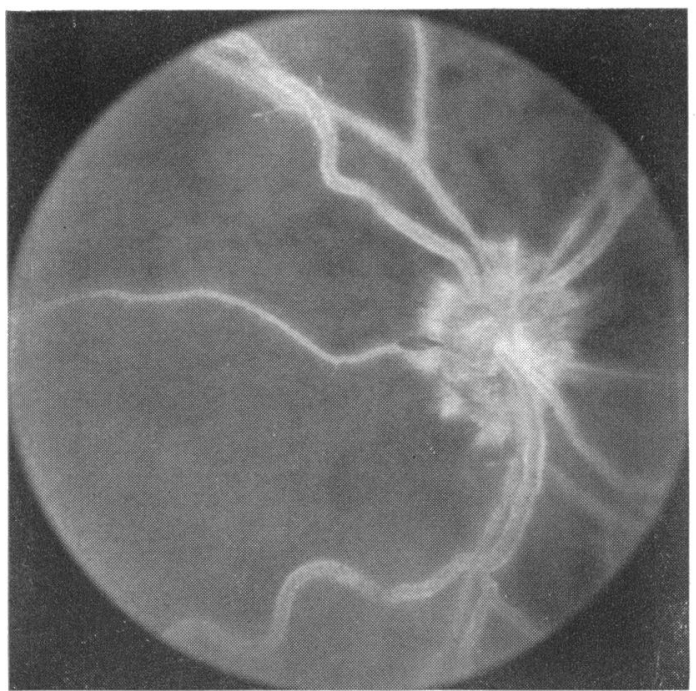

$(5 a)$

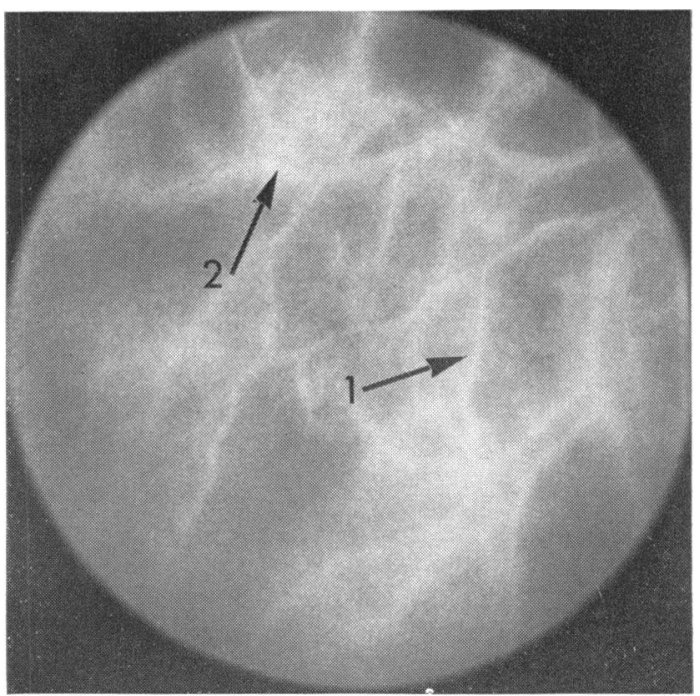

$(5 b)$

FIG. 5 Severe CRVO 7 weeks after first symptoms. (a) Complete capillary and small vessel closure at posterior pole. (b) Same angiogram as (a), inferior temporal periphery. Almost complete capillary closure, but arterioles (arrow I) and venules (arrow 2) perfused. All vessels leak fluorescein

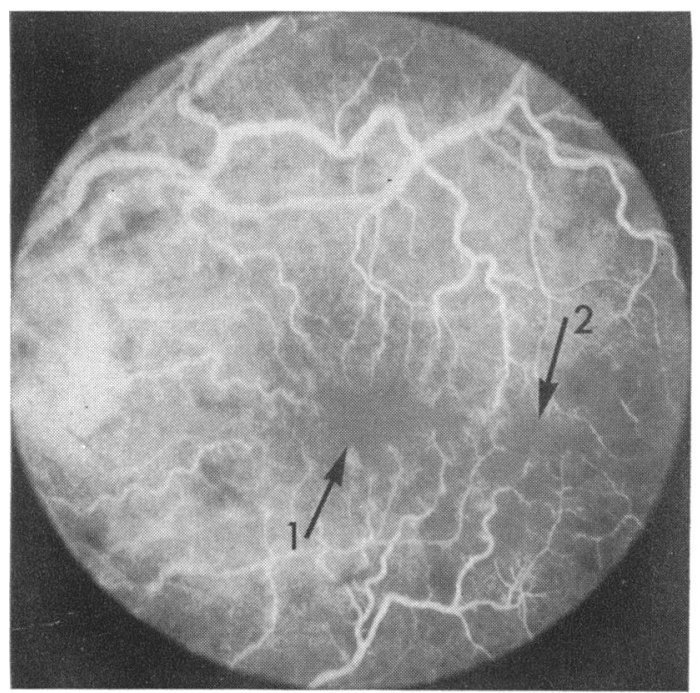

$(6 a)$

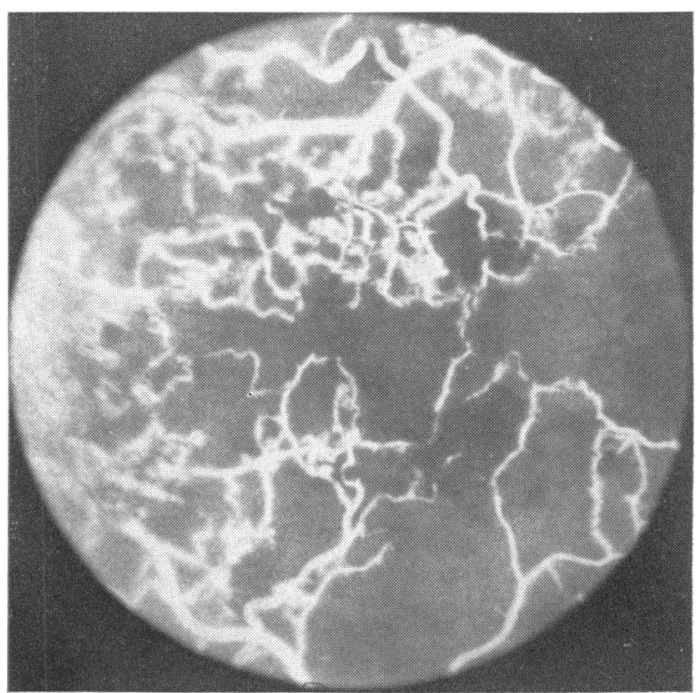

(6b)

FIG. 6 CRVO in acute stage. (a) Perifoveal arcade broken (arrow I), only small areas of capillary closure temporal to fovea (arrow 2). (b) Same as (a) one month later. Almost complete capillary closure throughout retina

in seven no or only a few macular capillaries were left, and in one eye the capillary details could not be assessed (Table II). All major blood vessels crossing non-perfused areas leaked fluorescein. Macular transit time was delayed in all cases and in half of them it was 5 seconds or more (Table IV). All these patients had a final visual acuity of less than $6 / 60$, and in five cases fluorescein angiography became impossible because of dense vitreous haemorrhage.

\section{FINAL OUTCOME}

The relationship between the final outcome and the extent and location of the capillary closure in the whole series of 75 eyes as it was seen at the three-month examination is shown in Fig. 8. 


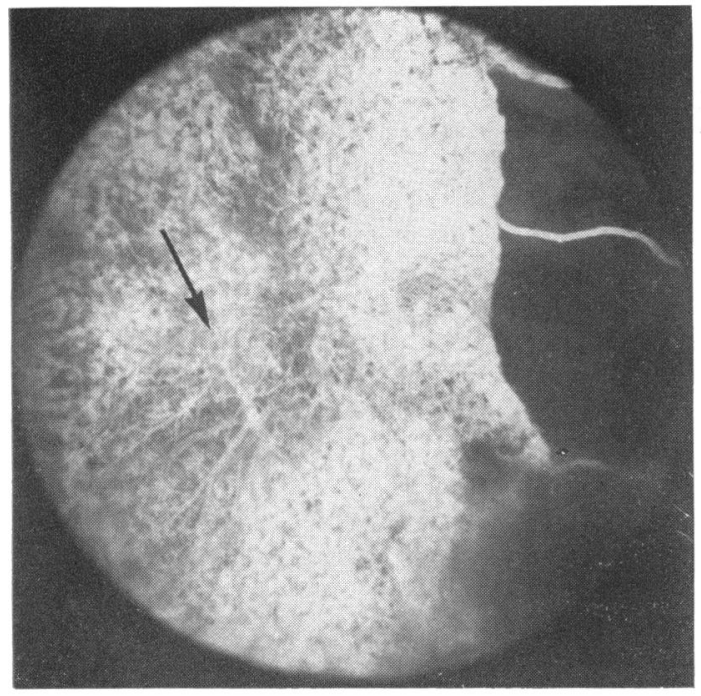

$(7 a)$

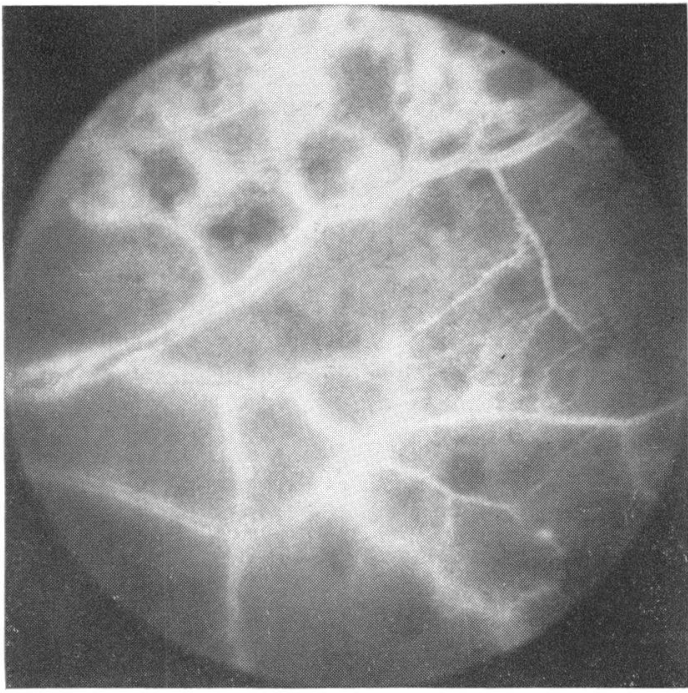

$(7 b)$

FIG. 7 (a) Severe CRVO with extensive new vessels (arrow marks centre of disc) 3 months after initial symptoms. Complete capillary closure in retina. (b) Same angiogram as (a), superior temporal periphery. Almost total capillary closure, remaining vessels leak fluorescein

It seems from these studies that out of 75 eyes with CRVO just over one-third (28) had a visual acuity of $6 / 12$ or better after one year. These patients all had good capillary perfusion and a near intact perifoveal capillary arcade in all but one patient. The macular transit time however was variable, as was the venous leakage.

Just under one-third (23) of the eyes became blind. Thrombotic glaucoma was the commonest cause. Large areas of central and peripheral nonperfusion were the hallmark in these eyes: in many no perifoveal capillaries were perfused. Leakage from veins also was more extensive and macular transit time often prolonged.

In the remaining 24 patients macular oedema and leakage from perifoveal capillaries predominated, as it did when they first presented.

\section{Discussion}

Previous studies of retinal branch vein occlusion have shown that the visual prognosis in eyes with an intact perifoveal capillary arcade is significantly better than in eyes with a broken arcade (Clemett, Kohner, and Hamilton, 1973). The present study shows that this also applies in CRVO; full resolution was seen only in eyes with an intact or nearly intact arcade. However, owing to permanently dilated and leaking capillaries, persistent cystoid macular oedema occurred in some, despite an intact arcade.

Fluorescein leakage from the retinal vessels indicates endothelial cell damage. In retinal vein occlusion this is due to increased intravenous pressure and to ischaemia of the vessel wall. In the mildest cases of CRVO only the terminal venules, the site of maximal increase in intravascular pressure, leak fluorescein and there may be minimal leakage from the main veins where they bend. Probably this leakage results from raised intraluminal pressure and not ischaemia. Leakage from the retinal capillaries is an indication of more extensive damage and a less favourable prognosis. Although a few eyes with macular capillary leakage resolved, some maculopathy or permanent macular oedema was the common outcome.

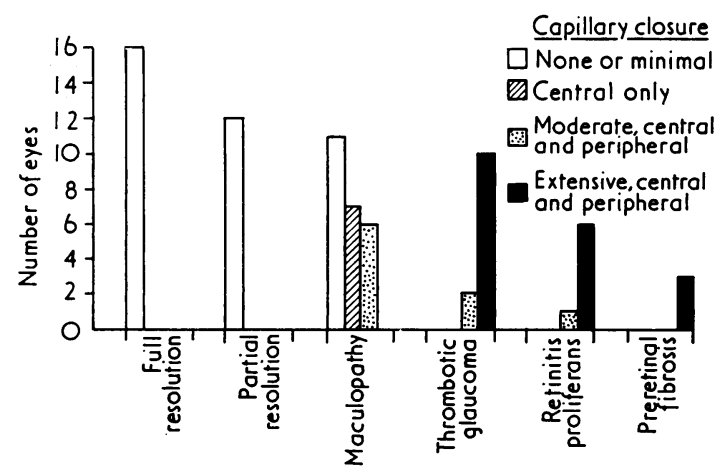

FIG. 8 Histogram showing relationship between final outcome and retinal capillary closure at 3-month examination in 75 eyes with CRVO 
The mechanism of capillary closure in RVO is not known. Experimental work (Hockley, Tripathi, Ashton, Kohner, Hamilton, Bird, and Rosen, in press) shows that soon after occlusion some of the vessels are narrowed (although not occluded) presumably by extracellular oedema, while others may be occluded as the result of stagnation thrombosis. Retinal capillary closure is common in all vascular retinopathies such as diabetic retinopathy, sickle-cell retinopathy, and Eales's syndrome. In all these conditions large areas of non-perfusion have been associated with new vessel formation at the disc and the retina.

In diabetes and in CRVO neovascularization of the angle followed by thrombotic glaucoma is also common. This is never seen in diabetes unless there are large areas of peripheral non-perfusion. In preliminary studies of over 600 cases of diabetic retinopathy seen at the Hammersmith Hospital there were only four with rubeosis in the absence of neovascularization (Grindle, 1976). Thrombotic glaucoma developed during the first three to four months in CRVO and new vessels of the disc and retina were not a prominent feature in these cases, probably because they take many months to develop. This poor correlation between iris and retinal neovascularization in CRVO has already been noted by Smith (I955). The stimulus for new vessel formation, both in the retina and the iris, has been thought to come from the ischaemic retina (Wise, 1956; Ashton, 196r ; Smith, 196r ; Kohner, Shilling, and Hamilton, 1976). The findings in this study support this theory, because both thrombotic glaucoma and retinal and disc vessels developed only in those with large areas of both central and peripheral non-perfusion. Indeed, it was impossible to predict from fluorescein angiograms which of these complications was most likely.

Hill (I 968) reported a correlation between 'mean retinal transit time' and venous dilatation in retinal vein occlusion. In this study macular transit time did not prove to be a valuable prognostic feature. While all patients with large non-perfused areas (and a poor prognosis) had some-often pronounced-slowing of the transit time, seven eyes with slow perfusion showed complete and two partial resolution. Leakage from arteries and veins and venous dilatation were unimportant findings compared with the site and extent of the capillary non-perfusion and the state of the perifoveal arcade.

In some of our cases the initial clinical and fluorescein angiographic picture of mild venous occlusion changed during the first three months to extensive capillary closure with poor visual prognosis. This shows that a visual prognosis within one month of presentation may be given only to those patients who have large non-perfused areas and in whom, therefore, the prognosis is poor. At three months an accurate prognosis can be given to all patients from the fluorescein appearances.

\section{Summary}

To determine the prognostic value of fluorescein angiograms in central retinal occlusion 75 patients presenting within the first three months of their initial visual symptoms were studied prospectively. The prognosis was found to be best (complete or partial resolution) in eyes with good capillary perfusion, an intact perifoveal capillary arcade, and leakage only from terminal venules and veins. A broken perifoveal capillary arcade and much capillary leakage, even in the absence of obvious capillary closure, were precursors of permanent macular oedema. All eyes with extensive capillary closure developed severe complications such as thrombotic glaucoma and neovascularization (preretinal fibrosis), and all became blind. Macular transit time and leakage from arteries and veins were not used as prognostic features.

Fluorescein angiography during the first month of the initial visual symptoms was of prognostic value only in those cases with poor prognosis. The three-month angiogram was an accurate indicator of the visual outcome in all cases.

\section{References}

ASHTon, N. (196I) Trans. ophthal. Soc. U.K., 81, 145

CLEMETT, R. S., KOHNER, E. M., and HAMILTON, A. M. (I973) Ibid., 93, 523

GASS, J. D. M. (1968) Arch. Ophthal. (Chic.), 80, 550

GRINDLE, J. (I976) Personal communication

HILl, D. W. (1968) Brit. F. Ophthal., 52, I

HOCKLEY, D., TRIPATHI, R., ASHTON, N., KOHNER, E. M., HAMILTON, A. M., BIRD, A., and ROSEN, D. (in preparation)

KOHNER, E. M., SHILlING, J., and HAMILTON, A. M. (I976) (In press)

SMITH, R. (1955) 'Acta XVII Concilium Ophthalmologicum, Canada and USA, I954', vol. 2, p. I I64. University Toronto Press, Chicago (1961) Trans. ophthal. Soc. U.K., 81, 125

Wise, G. N. (1956) Trans. Amer. ophthal. Soc., 54, 729 